\title{
Half greater than whole
}

WITH the steady decline in the number of those who go into productive industry in Britain and the steady rise in the number of people worrying about the problem, before the end of the century we expect these numbers to be equal and sometime early in the twentyfirst century to see the disappearance of the last industrial worker. The Commons Select Committee on Science and Technology is the latest to agonise over the trend (Commons paper 680, 11.15 ), and if anything may have helped to speed it on its way by publishing some bitter remarks from some of its witnesses. From Lord Bowden. formerly Principal of the University of Manchester Institute of Science and Technology, for example. about the hazards of industrial life. the rather unpleasant environment and the contempt of society at large for those who create the wealth which everyone wants to spend. Or from the Chairman of EMI. who declared that you wouldn't choose the industrial environment for security. money or professional satisfaction. Or even from $\mathrm{Mr}$ Varley, the Secretary of State for Industry. who said that 'to be a technologist or a manager within industry has been a pretty lousy job'.

The committee, in looking at university-industry relations. has bitten off more than it can reasonably chew. Some recommendations (see also page 311)- on the future of the National Research Development Corporation, on the moving of basic research out of governmental research laboratories, on the functioning of the Advisory Council on Applied Research and Development. on the establishment of a Minister of Science and Technology, and on the extension of the customer-contractor principle into the Science Research Council (SRC) with the Department of Industry (DoI) as customer for the applied research- seem too hastily put together and based on too scanty evidence to be taken seriously. For instance on this last issue the committec has failed to consider that SRC. unlike the other research councils, supports little applied research in its own institutions, and that the proposal would, therefore, let the DoI (already well equipped with laboratories) choose to support or kill research projects in university laboratories- -not, surely. the committee's intention.

It would be unfortunate, however, if the veritable deluge of half-worked-out proposals in the second half of the report were allowed to overshadow a valuable analysis, in the first half. of the development of postwar governmental support for science and technology education. It discusses the failures of new institutions and institutions with new names to convince bright students in large numbers that industry offered exciting prospects-a failure compounded by industry's own inability to project itself as a place where highly qualified scientists and technologists would reach the top. The report echoes a DoI assessment that 'the overall trend is a decline in the numbers and quality of qualified scientists and engineers and of supporting staff in key areas of manufacturing'.

Status and motivation seem to emerge as the villains of the piece. Young people do not see engineering as a worthy profession in which to exercise intellectual skills: as a result there is ton little understanding of what industry in all its complexity is about, or willingness to participate wholeheartedly amongst those 'forced' into it. The Select Committee, however. having inveighed against 'the distressing habit of attempting to bestow status (on academic institutions) by changing names'. proceeds to propose as one recommendation that Imperial College. UMIST. University of Strathclvde and some former Colleges of Advanced Technology should be labelled SISTERs (Snecial Institutions for Scientific and Technological Education and Research). This is a revival of a 1963 idea to give technology greater prominence. The Rector of Imperial College will no doubt be mildly surprised to find that the committee propose that applied science and engineering at Cambridge be also made into a SISTER 'to ensure the high status of SISTERs is recognised by the academic community.

The SISTER idea. unfortunately, is as poorly worked out as most of the committee's other ideas. To issue these institutions with revised charters limiting their functions to training and research in engineering and applied sciences would be to block all the fertile. increasingly necessary and in Britain often poorly developed cross-linkages into pure science. mathematics and economics. A dull narrow-minded product you'd get.

And yet the committee do at times get near to the centre of the problem: from early on in education the claims of industry and engineering are nothing like clearly enough presented. How many schools ensure that their pupils see a cross-section of industrial environments? How many industries make a serious attempt to get through to undergraduates, even to the extent of using them in vacations? The claims of an academic life are constantly being impressed on youngsters by their educational environment. Very often their only sight of industry before graduating is of strike picket lines on television news. There are some cautious ventures going ahead in this direction of mutual understanding, but it is up to the DoI. the Department of Education and Science and the Confederation of British Industry to stimulate much more. 